\title{
Studying Plant-Insect Interactions with Solid Phase Microextraction: Screening for Airborne Volatile Emissions Response of Soybeans to the Soybean Aphid, Aphis glycines Matsumura (Hemiptera: Aphididae)
}

\section{Lingshuang Cai ${ }^{1,2, \uparrow}$, Jacek A. Koziel ${ }^{1,3,4, \dagger, *}$ and Matthew E. O’Neal ${ }^{5, \dagger}$}

1 Department of Agricultural and Biosystems Engineering, Iowa State University, Ames, IA 50011, USA

2 DuPont Crop Protection, Stine-Haskell Research Center, 1090 Elkton Road, Newark, Delaware, DE 19711, USA

3 Department of Civil, Construction and Environmental Engineering, Iowa State University, Ames, IA 50011, USA

4 Department of Food Science and Human Nutrition, Iowa State University, Ames, IA 50011, USA

5 Department of Entomology, Iowa State University, Ames, IA 50011, USA

$\dagger$ These authors contributed equally to this work.

* Author to whom correspondence should be addressed; E-Mail: koziel@iastate.edu; Tel.: +1-515-294-4206; Fax: +1-515-294-4250.

Academic Editor: Mary Boyce

Received: 20 March 2015 / Accepted: 18 May 2015 / Published: 26 May 2015

\begin{abstract}
Insects trigger plants to release volatile compounds that mediate the interaction with both pest and beneficial insects. Soybean aphids (Aphis glycines) induces soybean (Glycine max) leaves to produce volatiles that attract predators of the aphid. In this research, we describe the use of solid-phase microextraction (SPME) for extraction of volatiles from A. glycines-infested plant. Objectives were to (1) determine if SPME can be used to collect soybean plant volatiles and to (2) use headspace SPME-GC-MS approach to screen compounds associated with $A$. glycines-infested soybeans, grown in the laboratory and in the field, to identify previously known and potentially novel chemical markers of infestation. A total of 62 plant volatiles were identified, representing 10 chemical classes. 39 compounds had not been found in previous studies of soybean volatile emissions. 3-hexen-1-ol, dimethyl nonatriene, indole, caryophyllene, benzaldehyde, linalool, methyl salicylate (MeSA), benzene ethanol, and farnesene were considered herbivore-induced plant volatiles (HIPVs).
\end{abstract}


For reproductive field-grown soybeans, three compounds were emitted in greater abundance from leaves infested with A. glycines, cis-3-hexen-1-ol acetate, MeSA and farnesene. In summary, SPME can detect the emission of HIPVs from plants infested with insect herbivores.

Keywords: herbivore-induced plant volatiles; SPME; GC-MS; Aphis glycines; soybeans; methyl salicylate (MeSA)

\section{Introduction}

Multitrophic interactions amongst host plants, herbivorous insects and natural enemies that feed on those herbivores can be tightly linked. Insect herbivores can produce a complex defensive response in their host plant [1]. A component of this response is the emission of volatiles that can play both a direct [1] and indirect defense [1] against plant pest. Such emissions are referred to as herbivore-induced plant volatiles (HIPVs). For insect herbivores, the indirect impact of HIPV involves attraction of the herbivores' natural enemies and the volatile response of plants can be unique to the species of herbivorous insects [2,3]. For example, a component of this response is methyl salicylate (MeSA), which is released by soybean leaves when fed on by herbivores, such as spider mites (Tetranychus urticae Koch; [4]) and the soybean aphids (Aphis glycines Matsumura [5]).

The invasion of $A$. glycines introduced a new, economic pest to soybean production in the United States [6]. Both seed-applied and foliar-applied insecticides are the primary tools for preventing yield loss from $A$. glycines in North America, resulting in a 130-fold increase in the their use for soybean production since the arrival of A. glycines in the U.S. However, a recent U.S. Environmental Protection Agency (EPA) review of the benefits associated with seed-applied insecticides suggest that this tool has no benefit for soybeans production and more specifically for protection from $A$. glycines. Natural enemies can be a significant source of mortality for early summer populations of A. glycines within the U.S. [7], but do not provide consistent biological control to completely replace insecticides. Recently, a field study using artificial sources of MeSA released in soybean fields resulted in a positive effect on the abundance of aphid predators and a negative impact on the abundance of $A$. glycines [8]. To what extent the positive impact of MeSA for the biological control of A. glycines can be further improved with additional HIPVs is not clear. Manipulating predators by combining HIPVs can increase the attraction of predaceous insects, though this increase may involve non-induced volatiles as well [9]. Therefore, a survey of the volatiles produced by soybeans, both induced and non-induced may play a significant role in future studies of HIPVs for management of A. glycines.

Several classes of volatiles have been identified from soybeans [10-13] (Table 1) using either Tenax-GC adsorbent or solid phase microextraction (SPME). The use of SPME to sample plant volatiles is attractive for several reasons. Air sampling pumps and solvents are not needed, and the headspace around a material can be readily sampled without maceration or homogenization of the plant material [14]. SPME has been used to sample volatiles from various parts of the soybean plant. Boue et al. [10] used SPME to detect differences in volatiles emitted from soybean seeds collected at distinct developmental stages. By inserting SPME fibers within sealed vials containing unprocessed soybean seeds, 49 compounds were recovered, 19 of which had not been reported previously from soybeans. Damiani et al. [13] 
collected volatiles using both SPME fibers and Tenax-GC adsorbent exposed to homogenized soybean leaves. The compounds identified using SPME were similar to those collected with sorbent Tenax [13]. The potential to expand upon the use of SPME in laboratory studies to field studies makes this method of volatile sampling attractive.

Table 1. Comparison of sampling and analytical methods used to characterize volatile organic compounds (VOCs) in soybean leaves and beans.

\begin{tabular}{|c|c|c|c|c|}
\hline Ref. & Sampling & $\begin{array}{c}\text { Sample } \\
\text { Preparation }\end{array}$ & Analyses & $\begin{array}{c}\text { Matrix and } \\
\text { \# identified compounds }\end{array}$ \\
\hline $\begin{array}{l}\text { This } \\
\text { work }\end{array}$ & $\begin{array}{l}\text { SPME ( } 85 \mu \mathrm{m} \text { Carboxen } / \text { PDMS); } \\
\text { Extraction conditions: } 25^{\circ} \mathrm{C}, 24 \mathrm{~h}\end{array}$ & SPME & GC-MS & $\begin{array}{l}\text { Soybean leaves } \\
\text { (A. glycines-infested and non-infested), } \\
62 \text { compounds }\end{array}$ \\
\hline $\begin{array}{l}\text { Zhu and } \\
\text { Park [11] }\end{array}$ & $\begin{array}{l}\text { Glass tube containing } 100 \mathrm{mg} \\
\text { Super Q }(80 / 100 \text { mesh })\end{array}$ & $\begin{array}{l}\text { Solvent } \\
\text { extraction. } \\
\text { Direct injection }\end{array}$ & $\begin{array}{l}\text { GC-EAD } \\
\text { (electro-antenno- } \\
\text { graphic detection) } \\
\text { GC-MS }\end{array}$ & $\begin{array}{l}\text { Soybean leaves } \\
\text { (A. glycines infested and non-infested), } \\
25 \text { compounds }\end{array}$ \\
\hline $\begin{array}{c}\text { Boue } \\
\text { et al. }[10]\end{array}$ & $\begin{array}{l}\text { SPME (100 } \mu \mathrm{m} \text { PDMS, } 50 / 30 \mu \mathrm{m} \\
\text { DVB/Carboxen/PDMS); } \\
\text { Extraction conditions: } 60^{\circ} \mathrm{C}, 1 \mathrm{~h}\end{array}$ & SPME & GC-MS & Soybeans, 49 compounds \\
\hline $\begin{array}{l}\text { Rosario } \\
\text { et al. }[12]\end{array}$ & $\begin{array}{l}\text { Dynamic headspace sampling; } \\
\text { Tenax-GC adsorbent }\end{array}$ & $\begin{array}{l}\text { Thermal } \\
\text { desorption }\end{array}$ & GC-MS & $\begin{array}{l}\text { Winged beans and soybeans, } \\
116 \text { compounds }\end{array}$ \\
\hline $\begin{array}{l}\text { Damiani } \\
\text { et al. }[13]\end{array}$ & $\begin{array}{l}\text { 1. Tenax-GC adsorbent, } \\
\text { 2. Purge and trap, } \\
\text { 3. SPME } 100 \mu \mathrm{m} \text { PDMS; Extraction } \\
\text { a } 45^{\circ} \mathrm{C}, 20 \mathrm{~min}\end{array}$ & $\begin{array}{l}\text { 1.Thermal } \\
\text { desorption } \\
\text { 2.SPME }\end{array}$ & $\begin{array}{l}\text { GC-MS } \\
\text { GC-FTIR }\end{array}$ & Soybean leaves, 9 compounds \\
\hline
\end{tabular}

We investigated the volatile response of soybeans to A. glycines using Carboxen/polydimethylsiloxane (PDMS) $75 \mu \mathrm{m}$ SPME fibers. Our objective was to determine if SPME could be used to identify compounds associated with $A$. glycines-infested soybeans grown in the laboratory and in the field. We hypothesize that SPME fibers can detect significant differences in the volatiles released in soybean plants that are non-infested or infested with $A$. glycines. We first focused on MeSA to determine if SPME fibers could detect if it was produced in greater amounts from $A$. glycines infested soybeans as previously documented. Then, we screened for potential new compounds that could serve as markers of infestation or improve the use of HIPV's for A. glycines management.

\section{Experimental Section}

\subsection{Aphis glycines Colony}

Aphids used within greenhouse-based experiments were from a colony maintained at the Soybean Entomology Lab at Iowa State University (ISU), Ames, Iowa. A. glycines were collected from soybean plants from multiple sites within Story County, Iowa. Aphids were kept on vegetation stage (V3-V6, 3-6 fully open, mature trifoliate leaves) soybean plants within multiple growth chambers (16:8 Light:Dark, $24{ }^{\circ} \mathrm{C}$ ). Plants were replaced every 2-3 weeks, with foliage removed from infested plants and attached to non-infested plants. 


\subsection{Volatiles from Soybeans with and without A. glycines: Vegetative-Stage, Greenhouse Grown Soybean}

Individual soybean plants were grown in pots $(13 \mathrm{~cm}$ diam.) with potting soil in a greenhouse (14:8 $\mathrm{L}: \mathrm{D}, 22^{\circ} \mathrm{C}$ ). Five plants were infested with 2 aphids placed on the youngest, mature leaf after plants reached the V3 stage. Plants were observed every $12 \mathrm{~h}$ to insure aphids successfully established, with an additional 10 aphids per plant added 2 days later. Infested plants were placed in a growth chamber (14:8 $\mathrm{L}: \mathrm{D}, 25^{\circ} \mathrm{C}$ ) and non-infested plants were kept in the greenhouse in which A. glycines were not present. Both sets of plants were watered every 2-3 days. On Day 15 and 16 we removed three leaflets of the youngest mature trifoliate from A. glycines infested and non-infested plants. All plants were in the early vegetative stage of growth (V5). Leaves were removed from one plant in $1 \mathrm{~h}$ intervals for a total of 6 plants on the first day and 4 on the second.

\subsection{Reproductive-Stage, Field Grown Soybean}

In late July, we collected leaves from soybean-aphid infested and non-infested soybean plants from a field on the ISU Research Farm. Although aphid populations were above 1000 per plant (M.O. personal observation) no insecticides were applied. Leaf tissue was collected in the same manner as with the greenhouse-grown plants, with 4 leaves selected without aphids. Although many plants were infested with $A$. glycines, we did find 4 plants without aphids on the youngest mature leaf. Leaves were removed from soybean plants in the reproductive stage with pods formed along the stem of the plant (R4).

\subsection{Volatile Emissions Screening with SPME and GC-MS}

SPME extractions were performed with $75 \mu \mathrm{m}$ Carboxen/PDMS fibers (Supelco, Bellefonte, PA, USA). Carboxen/PDMS coating is very efficient at extracting volatile organic compounds (VOCs) with molecular weight between 35 and 220. Other good SPME coating choices are PDMS/divinylbenzene (DVB) and DVB/Carboxen/PDMS. Screw-capped vials $(40 \mathrm{~mL})$, sealed with a PTFE-lined silicone septum, were used for storing soybean leaves and for HS-SPME sampling. Vials were placed at $25^{\circ} \mathrm{C}$ and SPME sampling started within $5 \mathrm{~min}$ from delivery from the greenhouse or field. Headspace sampling time was $24 \mathrm{~h}$ and it was selected to increase the extracted mass of compounds of interest and the number of compounds that could be identified. After extraction, the SPME fiber was removed from the vial and immediately inserted into the GC injection port for complete thermal desorption and analysis.

Multidimensional gas chromatography-mass spectrometry-olfactory (MDGC-MS-O) (from Microanalytics, Round Rock, TX, USA) was used for all analyses. The system integrates GC-O with conventional GC-MS (Agilent 6890N GC / 5973 MS from Agilent Inc., Wilmington, DE). The system was equipped with a non-polar pre-column $(12 \mathrm{~m} \times 0.53 \mathrm{~mm}$ ID (SGE BP-5+, SGE, Austin, TX, USA) and polar column ( $25 \mathrm{~m} \times 0.53 \mathrm{~mm}$ ID polar analytical column (SGE BP20, SGE) in series, as well as system automation and data acquisition software (MultiTrax ${ }^{\text {TM }}$ V. 6.00 and AromaTrax ${ }^{\text {TM }}$ V. 6.61, from Microanalytics and Chemstation ${ }^{\mathrm{TM}}$, from Agilent). The general run parameters used were as follows: injector, $260{ }^{\circ} \mathrm{C}$; FID, $280{ }^{\circ} \mathrm{C}$, column, $40{ }^{\circ} \mathrm{C}$ initial, $3 \mathrm{~min}$ hold, $7{ }^{\circ} \mathrm{C} / \mathrm{min}, 220^{\circ} \mathrm{C}$ final, $10 \mathrm{~min}$ hold; carrier gas, He. $\mathrm{m} / \mathrm{z}$ range was set between 33-280. Spectra were collected at 6 scans/s. The MS detector was auto-tuned weekly. 


\subsection{Chemical Analysis}

Compounds were identified using mass spectra and retention times of reference standards and/or mass spectra of Wiley library matches of greater than 70\% using the BenchTop/PBM (Palisade Mass Spectrometry, Ithaca, NY) search system. Reference standards were purchased from Sigma-Aldrich and included hexanal (98\%), 1-butanol, 3-methyl- (99\%), 3-octanone (98\%), 3-octanol (99\%), acetic acid (99.7\%), benzaldehyde (99\%), beta-elemene (99\%), methyl salicylate (99\%), trans-Caryophyllene (99\%), benzene ethanol (99\%), phenol (99\%), and indole (99\%), respectively. Compounds were identified with 2 sets of criteria: (1) match of the retention time on the MDGC capillary column with the retention time of pure compounds run as standards and (2) matching mass spectrums of unknown compounds with BenchTop/PBM MS library search system and spectrums of pure compounds. We confirmed the presence of MeSA from soybean leaves using pure, synthesized compound (from SigmaAldrich, St. Louis, MO, USA). Levels of MeSA were determined by monitoring ion $120 \mathrm{~m} / \mathrm{z}$ at $19.7 \mathrm{~min}$ GC column retention time. We compared the abundance of MeSA for infested and non-infested plants using the integrated peak area for the characteristic MeSA (120) ion.

In addition, we measured leaf area and the number of insects (aphids and thrips, Thysanoptera: Thripidae) on each excised leaf sampled. The number of insects (i.e., aphids, thrips) on the entire plant was also counted. Plants were co-infested with thrips within the greenhouse (common contamination) and therefore leaves with larger numbers of thrips ( $>9$ per leaf) and no aphids were removed from the analysis.

\subsection{Statistical Analyses}

We determined if the amount of a volatile compound collected from A. glycines infested and non-infested plants differed with a students' T-test. We used regression analysis to explain the variation in the amount of MeSA across all samples. Several independent variables were also incorporated within the regression analysis including leaf area, thrips per leaf, aphids per leaf and the total number of herbivores per plant. Outliers were identified, removed and the analysis repeated using a Satterthwaite correction for unequal variation between treatment groups. Outliers were identified as co-infested with thrips.

\section{Results and Discussion}

\subsection{Volatile Emissions from Vegetative-Stage, Greenhouse Grown Soybean}

We observed the largest number of thrips on any of the plants that were not infested with A. glycines. Due to this secondary infestation, we performed statistical analyses to determine if the MeSa emissions were confounded. Based on regression analysis, we observed a significant relationship between the number of thrips on leaves and the amount of MeSA collected $(F=59.15$, df $=1,8 ; P<0.001)$. When we combined samples, $87 \%$ of the variation in MeSA production was accounted for by a linear relationship to the number of thrips per leaf $\left(R^{2}=0.87,(y)=9.0 \times 10^{5}(\times)-8.7 \times 10^{5}\right)$. However, this relationship was consistent for both $A$. glycines infested and non-infested plants. Further regression analysis did not reveal significant relationships between MeSA and leaf area or aphids and thrips combined (analysis not shown). 
Comparison of total ion chromatograms (TIC) and single ion (120) chromatogram of headspace of leaves from non-infested and infested soybean plants grown in laboratory sampled is shown in Figure 1.

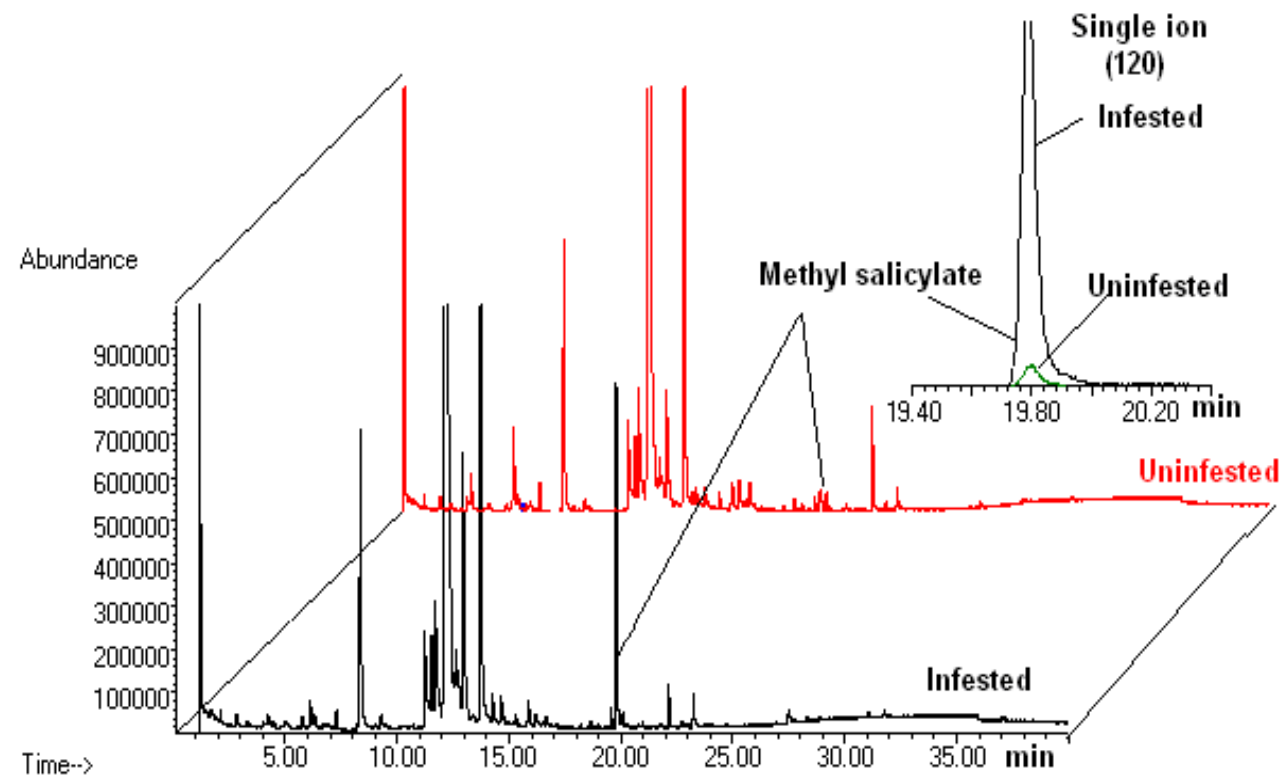

(A) Volatile emissions from greenhouse grown leaves.

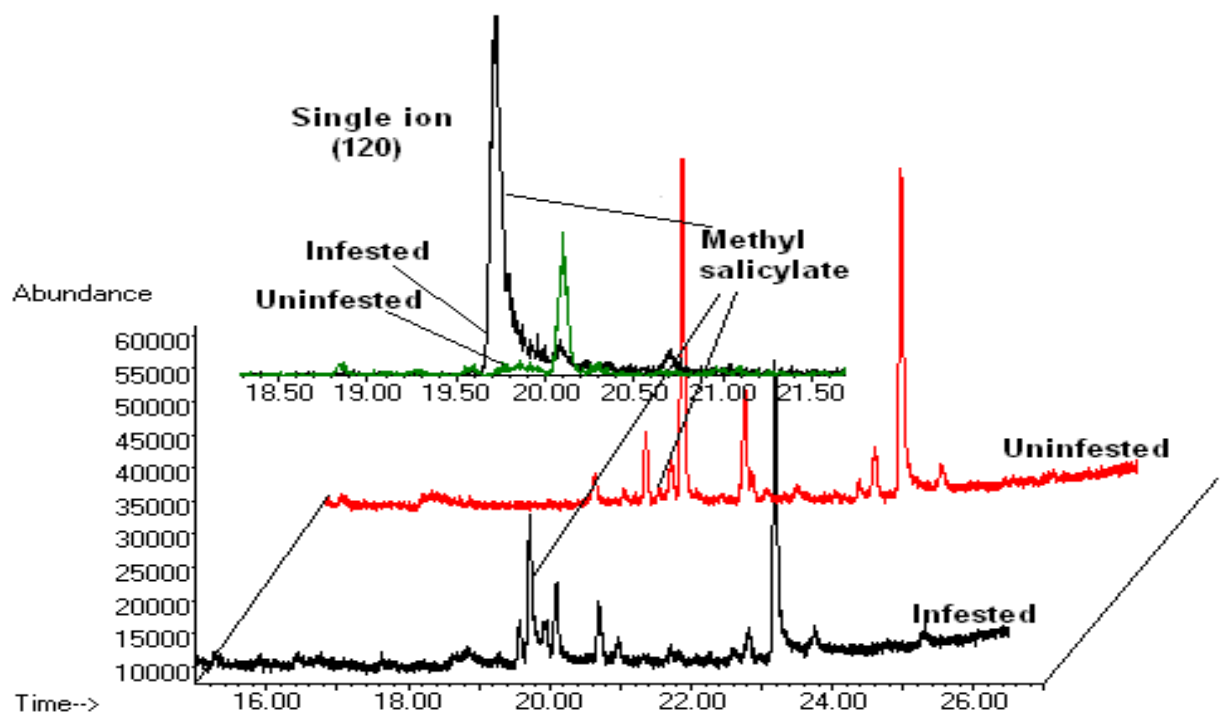

(B) Volatile emissions from field-grown leaves.

Figure 1. Comparison of total ion chromatograms (TIC) and single ion (120) chromatogram of headspace of leaves from non-infested and infested and heavy infested soybean plants grown in greenhouse (A) and grown in field (B) sampled with $75 \mu \mathrm{m}$ Carboxen/PDMS SPME fiber for $24 \mathrm{~h}$ at $25^{\circ} \mathrm{C}$.

A total of 62 volatile compounds (Table 2) emitted from soybean leaves were tentatively identified using HS-SPME-GC-MS, representing 10 chemical classes including alcohols (15), aldehydes (5), esters and lactones (13), ketones (5), amines and N- containing compounds (8), hydrocarbons (11), acids (2), S-containing compounds (2), and pyranes (1). 
Table 2. Preliminary identification of compounds emitted from soybean leaves growing in greenhouse.

\begin{tabular}{|c|c|c|c|c|c|c|c|c|}
\hline & $\begin{array}{c}\text { GC } \\
\text { column } \\
\text { RT } \\
(\mathbf{m i n}) \\
\end{array}$ & Compound & CAS & $\begin{array}{c}\text { MS } \\
\text { spectral } \\
\text { match } \\
(\%) \\
\end{array}$ & $\begin{array}{c}\text { Boue } \\
\text { l et al. } \\
{[10]} \\
\text { beans }\end{array}$ & $\begin{array}{c}\text { Rosario } \\
\text { et al. [12] } \\
\text { beans }\end{array}$ & $\begin{array}{c}\text { Damiani } \\
\text { et al. }[13] \\
- \\
\text { beans } \\
\end{array}$ & $\begin{array}{c}\text { Zhu and } \\
\text { Park } \\
{[11]} \\
\text { leaves } \\
\end{array}$ \\
\hline 1 & 2.06 & Acetic acid, methyl ester & $79-20-9$ & 35 & $\mathrm{y}$ & $\mathrm{y}$ & & \\
\hline 2 & 3.25 & Butanal, 2-methyl- & $96-17-3$ & 74 & & $\mathrm{y}$ & & \\
\hline 3 & 3.96 & 2,4-Hexadienal & $142-83-6$ & 63 & $\mathrm{y}$ & & & \\
\hline 4 & 4.16 & Propanenitrile, 2-methyl- & $78-82-0$ & 83 & & & & \\
\hline 5 & 4.36 & Trimethylsilanol & $1066-40-6$ & 69 & & & & \\
\hline 6 & 4.81 & 1-Penten-3-one & $1629-58-9$ & 38 & & & $\mathrm{y}$ & \\
\hline 7 & 5.45 & $\begin{array}{l}\text { Butanoic acid, 2-methyl-, } \\
\text { methyl ester }\end{array}$ & $868-57-5$ & 88 & & & & \\
\hline 8 & 5.70 & Propane, 1-chloro-2-methyl- & $513-36-0$ & 28 & & & & \\
\hline 9 & 6.01 & Butanedinitrile, 2,3-dimethyl- & $16411-13-5$ & 82 & & & & \\
\hline 10 & 6.23 & 2-Propanol, 2-methyl- & $75-65-0$ & 35 & & $\mathrm{y}$ & & \\
\hline 11 & 6.65 & Hexanal * & $66-25-1$ & 88 & $\mathrm{y}$ & $\mathrm{y}$ & $\mathrm{y}$ & \\
\hline 12 & 7.05 & 3,4-Dihydropyran & $110-87-2$ & 39 & & & & \\
\hline 13 & 7.23 & 1-Penten-3-ol & $616-25-1$ & 79 & & $\mathrm{y}$ & & \\
\hline 14 & 8.13 & 1-Butanol-, acetate & $123-92-2$ & 85 & & $\mathrm{y}$ & & \\
\hline 15 & 8.26 & 1-Butanol, 3-methyl- * & $123-51-3$ & 76 & & $\mathrm{y}$ & & \\
\hline 16 & 9.21 & cis-3-Hexenal & $6789-80-6$ & 68 & & & & \\
\hline 17 & 9.00 & 1-Butanol, 2-methyl- & $137-32-6$ & 31 & & $\mathrm{y}$ & & \\
\hline 18 & 9.00 & Cyclobutanone, 2, 2-dimethyl- & 1192-14-9 & 68 & & & & \\
\hline 19 & 10.58 & trans-2-Methyl-1, 3-pentadiene & $\mathrm{n} / \mathrm{a}$ & 79 & & & & \\
\hline 20 & 11.16 & 3-Octanone * & $106-68-3$ & 93 & $\mathrm{y}$ & $\mathrm{y}$ & & \\
\hline 21 & 11.48 & cycloproane, propyl- & $2415-72-7$ & 74 & & & & \\
\hline 22 & 11.65 & 3-Hexen-1-ol & $928-97-2$ & 69 & $\mathrm{y}$ & $\mathrm{y}$ & $\mathrm{y}$ & \\
\hline 23 & 11.98 & cis-3-Hexen-1-ol & 928-96-1 & 95 & & & $\mathrm{y}$ & \\
\hline 24 & 12.15 & cis-3-Hexen-1-ol, acetate & $3681-71-8$ & 76 & & & $\mathrm{y}$ & $\mathrm{y}$ \\
\hline 25 & 12.58 & 1,3-Pentadiene, 2-methyl- & $926-54-5$ & 83 & & & & \\
\hline 26 & 12.88 & 3-Octanol * & $589-98-0$ & 83 & $\mathrm{y}$ & $\mathrm{y}$ & & \\
\hline 27 & 13.30 & Acetic acid* & $64-19-7$ & 74 & & $\mathrm{y}$ & & \\
\hline 28 & 13.61 & 1-Octen-3-ol & $3391-86-4$ & 83 & $\mathrm{y}$ & $\mathrm{y}$ & $\mathrm{y}$ & \\
\hline 29 & 14.21 & Oct-1-en-3-one & $50306-18-8$ & 72 & & & & \\
\hline 30 & 14.58 & Cyclopropene, 3,3-diethyl- & $78578-86-6$ & 33 & & & & \\
\hline 31 & 14.95 & Benzaldehyde* & $100-52-7$ & 93 & $\mathrm{y}$ & $\mathrm{y}$ & & $\mathrm{y}$ \\
\hline 32 & 15.23 & gamma, Heptalactone & $105-21-5$ & 24 & & & & \\
\hline 33 & 15.80 & Linalool & $78-70-6$ & 31 & & & & $\mathrm{y}$ \\
\hline 34 & 16.13 & $2[5 \mathrm{H}]$-Furanone, 5-ethyl- & $2407-43-4$ & 50 & & & & \\
\hline 35 & 16.41 & Benzene, isocyano- & $931-54-4$ & 68 & & & & \\
\hline 36 & 16.40 & $\begin{array}{l}\text { Malonic acid bis-( 2-trimethylsilanyl-ethyl } \\
\text { ester) }\end{array}$ & $90744-45-9$ & 31 & & & & \\
\hline 37 & 16.80 & Thiophene, 2-pentyl- & $4861-58-9$ & 24 & & & & \\
\hline
\end{tabular}


Table 2. Cont.

\begin{tabular}{|c|c|c|c|c|c|c|c|c|}
\hline & $\begin{array}{c}\text { GC } \\
\text { column } \\
\text { RT } \\
(\mathrm{min}) \\
\end{array}$ & Compound & CAS & $\begin{array}{c}\text { MS } \\
\text { spectral } \\
\text { match } \\
(\%) \\
\end{array}$ & $\begin{array}{c}\text { Boue } \\
\text { et al. } \\
{[10]} \\
\text { beans } \\
\end{array}$ & $\begin{array}{c}\text { Rosario } \\
\text { et al. }[12] \\
\text { beans }\end{array}$ & $\begin{array}{c}\text { Damiani } \\
\text { et al. }[13] \\
- \\
\text { beans } \\
\end{array}$ & $\begin{array}{c}\text { Zhu and } \\
\text { Park } \\
\text { [11] } \\
\text { leaves } \\
\end{array}$ \\
\hline 38 & 17.08 & Benzoic, methyl ester & $93-58-3$ & 75 & & & & \\
\hline 39 & 18.13 & gamma, Hexalactone & $695-06-7$ & 88 & & & & \\
\hline 40 & 18.6 & 2-Cyclohexene-1,4-dione & $4505-38-8$ & 63 & & & & \\
\hline 41 & 18.81 & alpha -Copaene & $3856-25-5$ & 89 & & & & \\
\hline 42 & 18.96 & $2[5 \mathrm{H}]$-Furanone, 5-ethyl-, [R] & $76291-90-2$ & 72 & & & & \\
\hline 43 & 19.26 & E-2-Methyl-2-butenoate & $67883-79-8$ & 72 & & & & \\
\hline 44 & 19.51 & beta-Elemene * & $515-13-9$ & 98 & & & & \\
\hline 45 & 19.71 & Methyl salicylate * & $119-36-8$ & 95 & & & & $\mathrm{y}$ \\
\hline 46 & 20.03 & trans-Caryophyllene * & $87-44-5$ & 93 & & & & \\
\hline 47 & 20.21 & 2-Clohexene-1, 4-dione & $4505-38-8$ & 72 & & & & \\
\hline 48 & 20.73 & Benzenemethanol & $100-51-6$ & 95 & & & & \\
\hline 49 & 20.93 & cis-Ocimene & $3338-55-4$ & 61 & & & & \\
\hline 50 & 21.36 & Benzene ethanol * & $60-12-8$ & 85 & & & & $\mathrm{y}$ \\
\hline 51 & 21.80 & alpha, Farnesene & $502-61-4$ & 94 & & & & $\mathrm{y}$ \\
\hline 52 & 22.06 & Methyl ester of 2-oxo-hexanoic acid & $6395-83-1$ & 18 & & & & \\
\hline 53 & 22.68 & Phenol * & $108-95-2$ & 91 & & & & \\
\hline 54 & 22.85 & 2-Methyl-3-phenythiopropene & $702-00-1$ & 24 & & & & \\
\hline 55 & 22.96 & (E)-4,8-Dimethyl-1,3,7-nonatriene & & 54 & & & & \\
\hline 56 & 23.76 & Ionol & $4130-42-1$ & 76 & & & & \\
\hline 57 & 24.01 & Methyl anisate & $606-45-1$ & 93 & & & & \\
\hline 58 & 27.4 & 1-Dodecanamine, n,n-dimethyl-, & $112-18-5$ & 72 & & & & \\
\hline 59 & 28.25 & 4-Morpholineethanamine & 2038-03-1 & 63 & & & & \\
\hline 60 & 28.83 & Indole * & $120-72-9$ & 90 & & & & \\
\hline 61 & 30.98 & 5-Ethyl-1, 3-dihydro-1, 3-diiminoisoindole & $134940-70-8$ & 369 & & & & \\
\hline 62 & 31.66 & Morpholine, 4-octadecyl- & $16528-77-1$ & 72 & & & & \\
\hline
\end{tabular}

Twelve of these compounds were positively identified with reference standards, all others were identified by spectra library matches with 25 of those compounds having spectral library matches of $70 \%$ or more. Thirty-nine of the compounds in Table 2 have never been reported previously in studies of soybean volatile emissions [10-13]. Only 11 compounds were previously reported as those emitted from soybean leaves. Of the identified compounds, nine (3-hexen-1-ol, dimethyl nonatriene, indole, caryophyllene, benzaldehyde, linalool, MeSA, benzene ethanol, and farnesene) are considered herbivore-induced plant volatiles (HIPV). Of the compounds that are considered HIPV, only MeSA was more abundant on the A. glycines infested plants. Significantly more MeSA was produced by A. glycines infested than non-infested plants (Students T-test with Satterhwaite correction for unequal variances; $t=2.80, \mathrm{df}=4.2, P=0.05)$. 


\subsection{Volatile Emissions from Reproductive-Stage, Field Grown Soybean}

Comparison of total ion chromatograms (TICs) and single ion (120) chromatograms characteristic of MeSA for the headspace of leaves from non-infested and A. glycines-infested soybean plants grown in the field is shown in Figure 1B. The TICs were similar to those obtained from the leaves grown in the greenhouse. No thrips were observed on soybean leaves collected from the field, on either aphid infested or non-infested leaves. Infested soybeans leaves had an average of $31.3 \mathrm{~A}$. glycines (adults and nymphs) with a standard deviation of 7.5. We detected several compounds from these field grown soybeans that varied significantly between leaves infested and non-infested with A. glycines (Figure 2). There were four compounds that were found in greater abundance from non-infested leaves; acetone $(t=2.69, \mathrm{df}=6$, $P=0.04)$, 2-methyl furan $(t=5.39, \mathrm{df}=6, P=0.002)$, trans-caryophyllene $(t=3.38, \mathrm{df}=6, P=0.02)$ and alpha-humulene $(t=4.31, \mathrm{df}=6, P=0.005)$. Three compounds were found in greater abundance from leaves infested with $A$. glycines, cis-3-hexane-1-ol acetate $(\mathrm{t}=2.95, \mathrm{df}=6, P=0.03)$, MeSA $(t=12.33, \mathrm{df}=6, P=0.0001)$ and trans-beta farnesene $(t=25.14, \mathrm{df}=6, P=0.0001)$. Analysis of leaf area and MeSA revealed no significant relationship (analysis not shown).

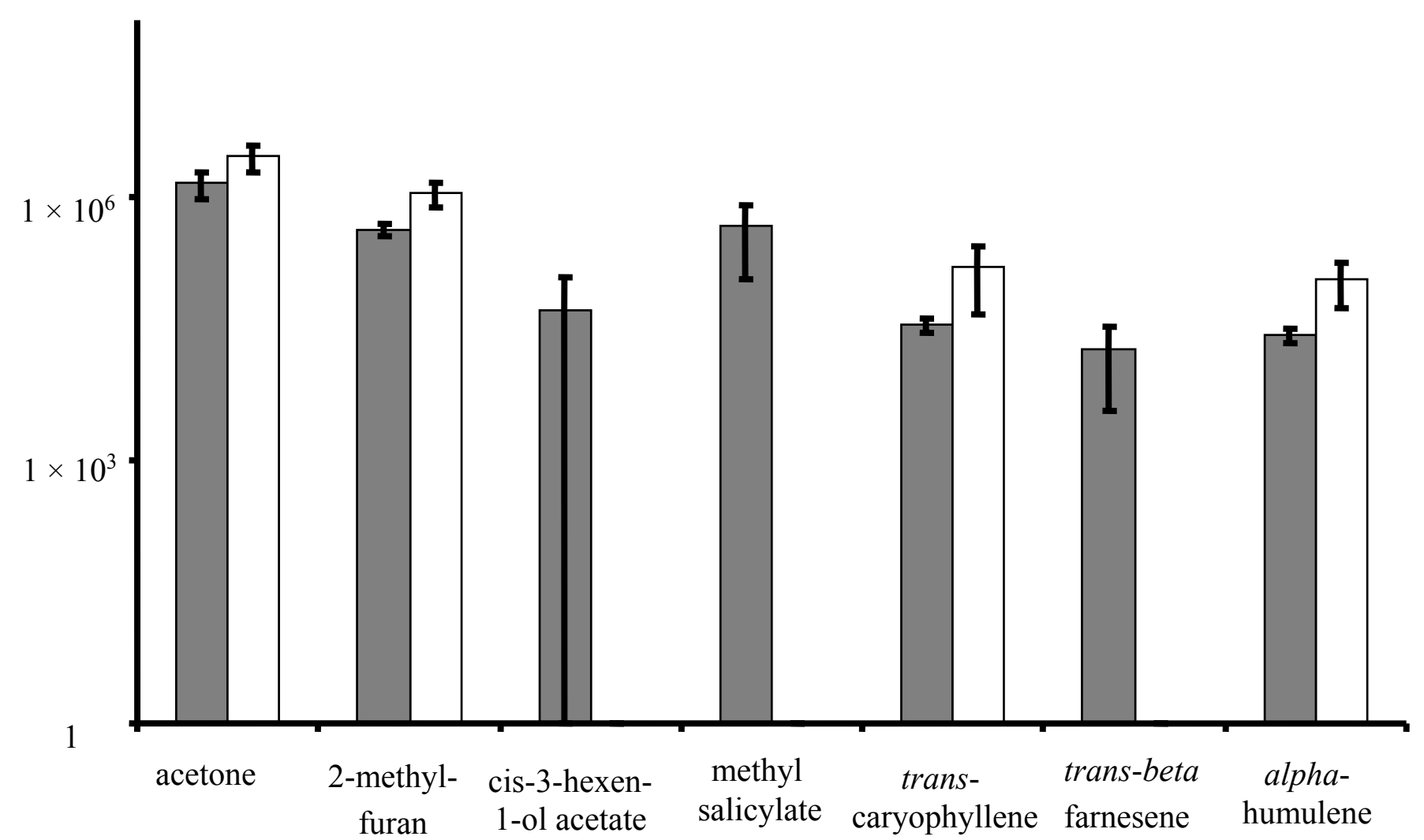

Figure 2. Mean (+SEM) abundance of several selected compounds per leaf on reproductive stage soybeans grown in the field with (gray bar) and without $A$. glycines (white bar). The concentration of each compound was significantly different between the two treatments (statistics reported in the text). 


\subsection{Discussion}

The results are consistent with those reported by Zhu et al. [11], with soybeans infested with A. glycines produce a different profile of volatiles from non-infested leaves. Significant differences between our methods and those of Zhu et al. [11] include (a) the method of volatile collection (passive sampling of enclosed leaf headspace with SPME fibers instead of Super Q absorbent), sorbent tubes and pump-aided gas sampling [11]), (b) the stage of soybean plants tested (reproductive here versus early vegetative stage in [11]), and (c) the use of field-grown soybean (in this research). Regarding the first significant difference, Carboxen/PDMS $75 \mu \mathrm{m}$ which targets compounds with a carbon number ranging from 2-12 was very useful in extracting a wide range of volatile and semivolative compounds emitted by leaves infested with $A$. glycines. We report 62 compounds that could be tentatively identified based on matching mass spectral profiles. More compounds could be detected and identified if different SPME coatings were used. Given their sensitivity and ease of use, experiments involving SPME to collect HIPVs in field conditions are warranted.

Despite these differences, we also observed greater emissions of MeSA, farnesene and cis-3-hexen1-ol acetate from A. glycines infested soybean leaves. Like Zhu et al. [11], we did not observe more cis3-hexen-1-ol on vegetative stage (V1-4) plants infested with A. glycines. However, when plants were in the reproductive stage we did observe more emissions of $c i s$-3-hexen-1-ol.

These data indicate that insect herbivores, in this case $A$. glycines and possibly thrips, are associated with greater MeSA volatile production from soybean leaves. From field-grown soybeans, we observed a greater difference in MeSA abundance between A. glycines infested and non-infested soybean leaves. Although the two experiments were conducted under very different growing conditions, it is interesting to note that the average abundance of MeSA from soybean leaves was greater from vegetative stage soybeans grown within the greenhouse $\left(\sim 5.0 \times 10^{6}\right)$ than from reproductive stage soybeans grown in the field $\left(\sim 0.45 \times 10^{6}\right)$. This order-of-magnitude difference may have been due to the absence of thrips, which were not found on any of the soybean leaves selected from the field. In addition to MeSA, we also collected several other compounds that are considered components of plant defense against herbivores; cis-3-hexen-1-ol acetate, farnesene, caryophyllene and humulene. Only cis-3-hexen-1-ol acetate and farnesene were produced by leaves with $A$. glycines. Curiously, caryophyllene and humulene were produced in greater abundance by leaves without aphids.

Our observations are consistent with a similar study of soybean response to T. urticae ('red spider' mite) [4], in which the headspace was sampled from non-infested and infested leaves removed from greenhouse grown soybean plants. Overall volatile production was greater on T. urticae infested leaves than non-infested leaves, with MeSA comprising 13\% of the total volatile output. MeSA was produced by mechanically damaged leaves, but the response was $50 \times$ as great on $T$. urticae infested leaves. This difference suggests that MeSA is an indirect defensive compound with limited direct impact, based on the acceptance of T. urticae for soybean [4] and the attractiveness of the predator Phytoseiulus persimilis to MeSA producing plants.

Rasmann et al. [15] has shown that the volatile response of corn to herbivore injury is not optimized in commercial varieties. To what extant breeding has removed or reduced the volatile response of soybeans to $A$. glycines is not known. Our results were accumulated with a commercially available cultivar (Syngenta NK S24-K4 RR) that has not been breed for A. glycines resistance. A greater response 
both in terms of amount and variety of volatiles produced could vary with lines that are either resistant our more closely related to the ancestral line of soybean. Our results suggest that soybean defenses against $A$. glycines may not be limited to antibiosis, which has been identified within soybean germplasm. An intriguing hypothesis is then posed: could soybean resistance or tolerance to A. glycines be selected for through a multitrophic interaction mediated by a kairomone like MeSA? Adding artificial sources of MeSA to soybean fields can increase the mortality of $A$. glycines [8]. It is not clear if selection for MeSA production through breeding could contribute to the suppression of A. glycines outbreaks. Furthermore, it is not clear if the additional compounds we identified as being produced on A. glycines infested leaves (cis-3-Hexen-1-ol acetate and farnesene, Figure 2) can be added to artificial sources of MeSA to improve upon the biological control of A. glycines population in North America.

\section{Conclusions}

Passive air sampling and screening of volatiles emitted by infested and non-infested soybean leaves with SPME was successful. We identified 62 compounds, i.e., adding significantly more to the list of compounds emitted by soybean leaves. We detected several compounds that varied significantly between leaves infested and non-infested with A. glycines. We observed greater emissions of MeSA, farnesene and cis-3-hexen-1-ol acetate from A. glycines infested soybean leaves. Like Zhu et al. [11], we did not observe more cis-3-hexen-1-ol on vegetative stage (V1-4) plants infested with $A$. glycines. However, when plants were in the reproductive stage we did observe more emissions of cis-3-hexen-1ol. There were four compounds that were found in greater abundance from non-infested leaves; i.e., acetone, furan, caryophyllene, and humulene. These compounds are considered HIPVs. Both these induced compounds, as well as the non-induced ones, described herein should be considered as candidates for future improvements on the attractiveness of MeSA to increase predators of $A$. glycines.

\section{Acknowledgments}

The authors would like to thank Steven Trabue, USDA-ARS in Ames, IA for helpful discussions on this manuscript. This work was supported by the USDA National Institute of Food and Agriculture, Hatch project \#233507, and by State of Iowa funds.

\section{Author Contributions}

J.K., L.C., and M.O. conceived and designed the experiments; L.C. and J.K. performed most of the experiments; L.C. analyzed the chemical data; M.O. performed statistical analyses, contributed soybean leaves and supervised their growth and leave collection; J.K., L.C., and M.O. wrote the paper.

\section{Conflicts of Interest}

The authors declare no conflict of interest.

\section{References}

1. Cardoza, Y.J.; Alborn, H.T.; Tumlinson, J.H. In vivo volatile emissions from peanut plants induced by simultaneous fungal infection and insect damage. J. Chem. Ecol. 2002, 28, 161-174. 
2. deBoer, J.G.; Posthumus, M.A.; Dicke, M. Identification of volatiles that are used in discrimination between plants infested with prey or nonprey herbivores by a predatory mite. J. Chem. Ecol. 2004, 30, 2215-2230.

3. De Moraes, C.M.; Lewis, W.J.; Pare, P.W.; Alborn, H.T.; Tumlinson, J.H. Herbivore-infested plants selectively attract parasitoids. Nature 1998, 393, 570-573.

4. Van Den Boom, C.E.; Van Beek, T.A.; Posthumus, M.A.; De Groot, A.; Dicke, M. Qualitative and quantitative variation among volatile profiles induced by Tetranychus urticae feeding on plants from various families. J. Chem. Ecol. 2004, 30, 69-89.

5. Fox, T.B.; Landis, D.A.; Cardoso, F.F.; DiFonzo, C. Predators suppress Aphis glycines Matsumura population growth in soybean. Environ. Entomol. 2004, 33, 608-618.

6. Ragsdale, D.W.; Landis, D.A.; Brodeur, J.; Heimpel, G.E.; Desneux, N. Ecology and management of the soybean aphid in North America. Ann. Rev. Entomol. 2011, 56, 375-399.

7. Fox, T.B.; Landis, D.A.; Cardoso, F.F.; DiFonzo, C. Predators suppress Aphis glycines Matsumura population growth in soybean. Environ. Entomol. 2004, 33, 608-618.

8. Mallinger, R.E.; Hogg, D.B.; Gratton, C. Methyl salicylate attracts natural enemies and reduces populations of soybean aphids (Hemiptera: Aphididae) in soybean agroecosystems. J. Econ. Entomol. 2011, 104, 115-124.

9. Mumm, R.; Dicke, M. Variation in natural plant products and the attraction of bodyguards involved in indirect plant defense. Can. J. Zool. 2010, 88, 628-667.

10. Boue, S.M.; Shih, B.Y.; Carter-Wientjes, C.H.; Cleveland, T.E. Identification of volatile compounds in soybean at various developmental stages using solid phase microextraction. J. Agric. Food Chem. 2003, 51, 4873-4876.

11. Zhu, J.W.; Park, K.C. Methyl salicylate, a soybean aphid-induced plant volatile attractive to the predator Coccinella septempunctata. J. Chem. Ecol. 2005, 31, 1733-1746.

12. del Rosario, R.; de Lumen, B.O.; Habu, T.; Flath, R.A.; Richard, M.T.; Teranishi, R. Comparison of headspace volatiles from winged beans and soybeans. J. Agric. Food Chem. 1984, 32, 1011-1015.

13. Damiani, P.; Cossignani, L.; Castellini, M.; Bin, F. Clean recovery and HRGC-MS/HRGC-FTIR identification of volatiles from soybean (Glycine max). Ital. J. Food Sci. 2000, 2, 175-182.

14. Augusto, F.; Lopes, A.L.E.; Zini, C.A. Sampling and sample preparation for analysis of aromas and fragrances. TrAC Trends Anal. Chem. 2003, 22, 160-169.

15. Rasmann, S.; Kollner, T.G.; Degenhardt, J.; Hiltpold, I.; Toepfer, S.; Kuhlmann, U.; Gershenzon, J.; Turlings, T.C.J. Recruitment of entomopathogenic nematodes by insect-damaged maize roots. Nature 2005, 434, 732-737.

(C) 2015 by the authors; licensee MDPI, Basel, Switzerland. This article is an open access article distributed under the terms and conditions of the Creative Commons Attribution license (http://creativecommons.org/licenses/by/4.0/). 